\title{
Mobile Device Interaction in Ubiquitous Computing
}

\author{
Thorsten Mahler and Michael Weber \\ University of Ulm, Institute of Media Informatics
}

Germany

\section{From Computing Machines to Personal Computers}

The $20^{\text {th }}$ century has seen the rise of the computer. In the early days of the 40 s a computer was a big machine filling a whole room working with bulbs. New technologies decreased its size to a machine as big as a closet, sometime later to a size fitting onto a desk. Along with the miniaturization the new technology made the computer as we know it today affordable for the everyday user. This made the personal computer to an omnipresent and universal tool for a vast number of users with very different expertise.

The human computer interface has evolved tremendously since its first days. Early computers had to be reconfigured through cables on patch fields and operated by switches. With the introduction of text displays and keyboards computers became a direct interactive tool being operated primarily through command line interfaces. The invention of graphic user interfaces and the mouse as a pointing device led to graphical window systems, the desktop metaphor and direct manipulation.

Notably, the inventions enabling these graphical user interfaces persistent until today where made years before their first useful application. The first mouse, presented in 1968 by Douglas Englebart did not get much attention because there was no need for a pointing device as there was no graphical user interface. The graphical user interface was invented in 1981 by Xerox Parc and introduced to the broad public three years later with the Apple Macintosh. Currently we are in a similar situation concerning interaction styles and metaphors in ubiquitous computing. Several exemplified solutions are being reported, but the breakthrough of the most likely to be used metaphors and interaction techniques is not revealed yet. (see for example Norman, 1998)

Besides the development of new technologies, we can observe a dramatic shift in the typical user of a computer from operators and programmers to non-expert users, which are most often not specifically trained to use computers. This leads towards user centred development and design approaches to better cover and understand the needs of the various user groups and to incorporate this knowledge into the design process and the products.

\subsection{The Paradox of Technology}

From the invention of first computing machines to today's personal computers we can state the turning away from technology centred design to user centred design. This tendency 
holds for the development of hardware but is especially true for the evolution of the user interface. But this development is not linear (see Fig. 1). Rather, the invention of new technology and its application makes new devices hard to use, the complexity level is high. After a while, when the technology is mastered and the needed interaction paradigms are identified, the complexity level drops. Along with it, users are getting accustomed to the technology, the usage get easier and easier. Some time later, the mature interface for the new device is found and people use the technology naturally, the complexity level gets low, the device usable. When this point is reached, new features will be added to the device making it more complex again, resulting in a rising complexity level. The paradox of technology starts again (Norman, 1988).

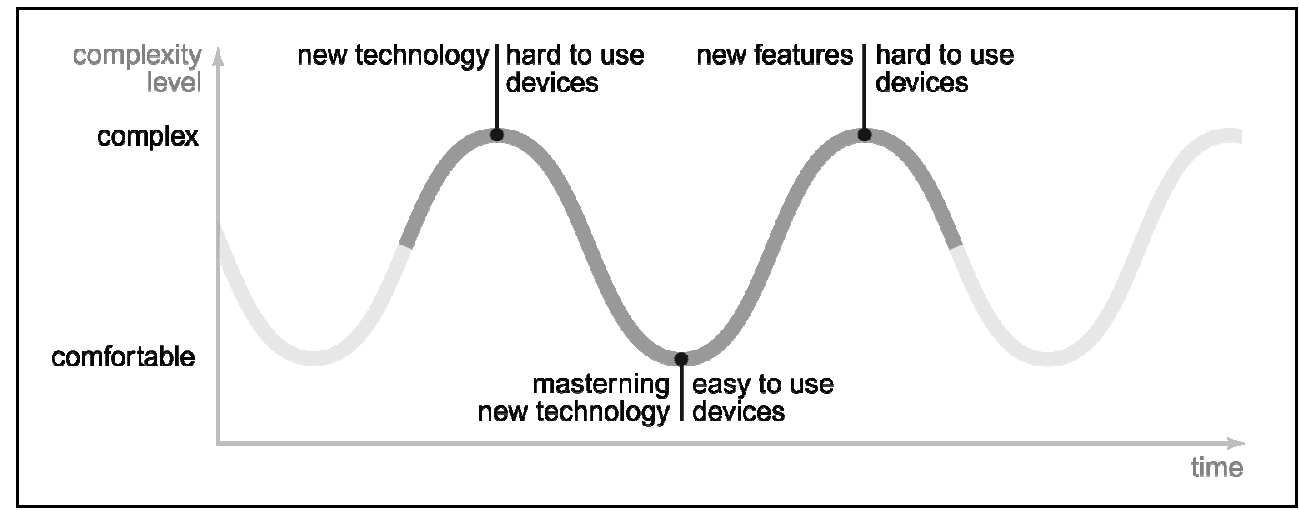

Figure 1. The Paradox of Technology (figure developed after Norman, 1988)

\subsection{The vision of Transparency and Ubiquity: Ubiquitous Computing}

The development of ever smaller, faster and more equipped devices makes way for mobile computing resulting in a change of the ways computer are used. Mobile computers free the user from his desktop, due to the portability of devices and also due to wireless communication technologies. However, the increasing number of devices carried posse new problems but allow for new ways of interaction. A user nowadays does not work with only one computer but with an ever increasing number of devices as more and more devices get computerized. These devices invade our homes and environments with effects not yet known and not yet understood. But concepts are evolving to deal with the new challenges and ways are researched to make the new possibilities usable and comfortable for everyday use (Messeter, 2004).

In his visionary article "The computer in the 21 st century" Mark Weiser (Weiser, 1991) formulates the next step in computerization. He coined the term ubiquitous computing. In his vision the miniaturization of the computer is leading to a world with computers everywhere enhancing artefacts intertwining the real and the virtual world. He states the renouncing of the personal computer as a single universal tool. Instead his vision propagates the use of multiple connected and invisible computers together. The furthermost implication of his vision and the goal of the new paradigm are the human centred direct interaction and problem solving in the real world as he states "ubiquitous computing, $[. .$.$] , resides in the human world and pose no barrier to personal interactions" (Weiser,$ 1991). 
In consequence the human user is able to concentrate on his task on hand eliminating the struggle with today's interfaces as they are unnoticeably being pushed to the background. The final goal is a world enhanced by computers being seamlessly integrated into our real life and our surroundings. There shall not be a technical barrier as there is today for lots of non expert users. Instead the computer should be integrated seamlessly, the user not being aware of its presence.

\subsection{Virtuality Continuum}

The convergence of virtual and real worlds exceeds the bounds of traditional understanding of computing and slowly blurs the formerly clearly separable areas. This is one major characteristic of interaction in ubiquitous computing where we witness the integration and merging of the physical world represented by real life objects and the virtual world represented by computer-generated visualizations or digital data in general.

Milgram and Kishino (Milgram \& Kishino, 1994) conceived the range of possible mixtures as the Virtuality Continuum (Fig. 2). At the one end (on the left of the figure) there are real environments consisting only of real objects, at the other extreme there are purely virtual environments. Depending on the extent of virtuality, Milgram and Kishino distinguish between Augmented Reality (AR) and Augmented Virtuality (AV). They call this span Mixed Reality (MR).

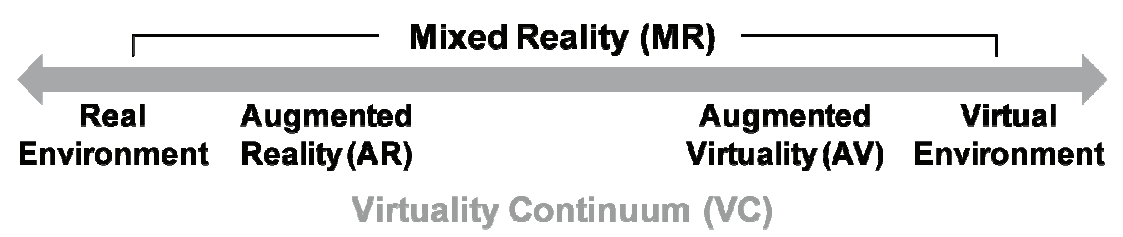

Figure 2. The Virtuality Continuum (Milgram \& Kishino, 1994)

According to Azuma a Virtual Environment, more commonly known as Virtual Reality (VR) is a completely synthetic immersive world in which the user has no notion of the real world around him. In contrast to that, Augmented Reality (AR) rather uses superimposition to enhance the real world wit virtual objects. Thus, the user stays in the real world and virtual objects are composed into the real scene (Azuma, 1997).

The goal of Milgram and Kishino is to describe a taxonomy to distinguish and categorize projects in the field of Mixed Reality and set them in relation with respect to their degrees of reality or virtuality. Thus they define virtuality as a fully closed computer generated world in which the user can totally immerse. Such a virtual reality does not necessarily convey the laws of physics of time, it only has to be consistent and reasonable enough to be able to immerse. Such virtual worlds are produced by projection screens surrounding the user potentially wearing shutter-glasses to get a 3-D impression (Weber \& Hermann, 2008).

Milgram and Kishino propose three aspects to further clarify the merging of real and virtual worlds. On first extend they distinguish which Extend of World Knowledge is known. This unites the degree of knowledge of the whereabouts of objects in a special mixed reality environment with their understanding. Only a complete understanding of every object and every object's specific location makes a fully immersive and superimposed mixed reality possible. Without the exact positioning and registration in the scenery the relation of objects 
cannot be visualized seamlessly. Without the understanding of objects their specific behaviour cannot be simulated. Furthermore an enhanced visual representation is not possible without specific knowledge of objects (cf. also to section 1.5).

The second dimension Milgram and Kishino define is the reproduction fidelity which denotes the quality with which the whole mixed reality scene is presented. It is clear, that high resolution representations with high colour quality and depth differ from simple wire frame representations. So this dimension tackles the quality of the rendering of virtual objects as well as the reproduction of real objects.

Finally they define the dimension Extend of Presence Metaphor (EPM). The EPM denotes on which extend the user feels present in the Mixed Reality. This dimension has a strong relation with the used hardware of the mixed reality application. Is it egocentric or exocentric, is the system real time capable and does it allow for seamless immersion.

Mixed Reality makes use of real world objects to some extent. The immersion gets harder and harder to be achieved the more interaction with the real environment shall be supported. Therefore the virtual objects have to behave more and more like real objects if a consistent feel of the whole Mixed Reality is desired.

Notably, Milgram and Kishino focus on visual displays, which are by far the most important output technology being used for Mixed Reality. Nevertheless, there are other thinkable virtual augmentations to reality such as auditory or haptic augmentation. Whereas Cohen focuses on enhancing user interfaces by speech (Cohen, 1992), Rath and Rocchesso for example use pure sound to enhance interaction. Their rolling ball example renders a bar to a virtual balance, feedback on the configuration is given by sound, which a rolling ball would make, when rolling according to the angle in which the bar is held (Rath \& Rocchesso, 2005). Another possibility lies in the haptic feedback of virtual objects (Shimoga, 1992). However, this needs a considerable lot of additional hardware like gloves which results in a more invasive application.

\subsection{Tangible Interaction}

With the vision of ubiquitous computing and its final goal to bring the virtual world into the real world it is only consequent to affect the virtual representations and objects through interaction with real life artefacts. As described by Holmquist et al. (Holmquist et al., 2004) there is a lot of research done in this domain focussing on different aspects according to the primary goal they pursue: graspable interface, tangible interface, physical interface, embodied interface, to name just a few. Yet the principal goal remains the same, the enrichment of virtual interaction by physicality.

One of the first to describe this link are Ishii and Ullmer in their paper "Tangible Bits" (Ishii \& Ullmer, 1997). Based on their observation that, by now, we are living almost constantly wired between the physical environment and cyberspace, they introduce the coupling of everyday objects with virtual information, the coupling of "Bits and Atoms" as they call it, to overcome this division and "rejoin the richness of physical world HCI like in precomputer era". Their visionary tangible bits allow for natural interaction rendering real life objects into tools, their interaction having effect on virtual objects. Such interaction is not only limited to objects as such but can also take place with a whole room, a wall or a space in general. Additionally Ishii and Ullmer tackle a very important fact: they distinguish between in focus action and background awareness. Following our natural way of perceiving our surrounding, ubiquitous computing and spatial interaction allow for 
peripheral perception and ambient artefacts. Consequently they develop the vision of ubiquitous computing into multi-sensory interaction and experience of digital information situated in natural space.

To clear the understanding of tangible interfaces Hornecker and Buur present a framework for tangible interaction concepts (Hornecker \& Buur, 2006). They describe four criteria on which basis they rate tangible interfaces as being shown in Fig. 3.

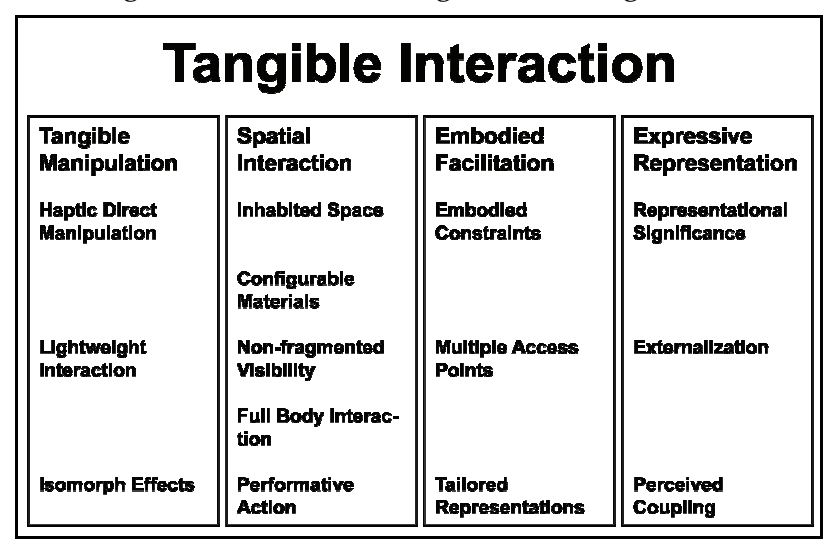

Figure 3. Tangible Interaction Framework (Hornecker \& Buur, 2006)

The first dimension, Tangible Manipulation, reflects the bodily interaction with a physical object. As each object for tangible interaction is simultaneously interaction device, interface and object the key aspects here are the quality of the mapping between action and effect along with the direct manipulation and how explorative the interface is. This tackles above all whether the effects of the object interaction are easily reversible and thus easy learning of object functionality is feasible.

The second dimension tackles the space in which the interaction takes place. The pure action of manipulating an object requires movement in space and particularly movement of the body itself. The sole body can even be seen as a special interface. Thus this category measures how the performative action itself has influence on the effect. Furthermore it tackles the meaning of space itself, if the position or the configuration of an object is meaningful and moreover if these properties can be configured.

Embodied Facilitation questions the constraints introduced by the object. To unburden the user interfaces should build on users' experience and the physical shape of the object should inspire the user with the desired action and effect. Detached from the Embodied Facilitation, the dimension Expressive Representation is proposed to measure the mapping itself. How clear is the coupling of the digital and real representation and are they of the same strength and importance. Does the object represent the virtual data and is it perceived as that. Hornecker and Buur describe this as being able to use objects as "props to act with", giving discussion a focus. Another interesting point made here is the transition of digital benefits. This dimension also measures to which extend props can record their configuration themselves and thus for example being able to undo changes, a functionality we are very used to in digital life. (Hornecker \& Buur, 2006)

Besides the elaboration of the framework, Hornecker and Buur mention another very interesting point: The possibility of digitally enhancing real objects allows for bringing 
together hard, complicated task with simple objects. The most direct mappings may therefore not always be the best way as this reduces the opportunities of rich interaction and manipulation of virtual information.

\section{Enhancing Everyday Objects}

The merge of the virtual and real world leads to problems concerning the handling of augmented objects and their digital representative.

different people. She particularly examined the connection people make between memories and physical objects. Especially the connection between personal souvenirs and holiday memories are characterized and based on the results a tangible user interface for personal objects created (van den Hoven \& Eggen, 2005). Their work with personal souvenirs shows another interesting point. Physical objects can already be connected with a mental model. That means that personal objects have personal meaning for a single user or very few users. They also define the term generic objects as a physical object that is not bound to an existing mental model for multiple users (van den Hoven \& Eggen, 2004).

If we expand these findings on everyday objects, ready mades, we can find up to three different links for a physically enhanced object:

1. Physical linkage introduced by physical constraints and learned knowledge about the used object.

2. Personal linkage between a known object and a personal occurrence.

3. Digital linkage between the object and the digital representative.

The potential of personal objects and the affiliated existing mental model is recognized as one of the most interesting couplings for tangible interfaces by other researchers as well (see Ullmer \& Ishii, 2001).

The desired seamless augmentation introduces the problem, that users are not always aware of the artefact's functions. As described above the unawareness can be due to different reasons: The physical linkage of the object may contradict the digital representation. For instance the learned knowledge about an object may be completely rational in a certain context but not understandable per se. For instance, in the MediaCup project augmented cups can detect whether they hold freshly brewed coffee and if there are other cups in the vicinity; if so, automatically a meeting context is assumed and the room is booked for the group (Beigl et al., 2001).

The personal or social linkage of an object may contradict a digital representative or may not be obvious for certain people.

The digital linkage is per se not existent in the real world and thus may remain undiscovered at all. Or, what is even more undesirable, interaction with a certain digitally enhanced object can trigger completely unexpected and unforeseen digital actions.

Clearly, these breaks in the mental model of our mixed surroundings are of no great impact at the time of set up. But as technology constantly pushes the bounds further and further these problems are important research challenges, not only for special solutions, but especially for complex and mixed environments.

Closely coupled with the raised problem of digital awareness is the question of how an object gets linked to a digital representation in general. To clarify this question we propose to divide the problem into three parts, the starting problem, the configuration problem and the interaction problem. 
Clearly, the use of beforehand unknown personal objects introduces the problem of how to link an object with a certain digital representation or action. This is especially true for objects that do not have an enhancement. So this is the question of how to supply an object with functionality in the first place.

Related to the starting problem is the question of how a linkage between object and digital representation can be changed or adjusted. We call this the configuration problem. In contrast to the starting problem, changes and adjustments have to be done while running the system because the very nature of mixed reality is the seamless integration and therefore the use of objects as an integral part. In conclusion this prohibits a shutdown and restart of a complete system. This is especially true for coming mixed reality environments will be inherently multi user systems.

This poses a third question: the question of how to interact with a real physical object on a purely digital basis. The interface itself is widely recognized to be an integral part of an enhanced object (see for example Ishii \& Ullmer, 1997) but how interfaces could look like in mixed reality environment needs further investigation. This is especially true for readymade objects that do not need a display of its digital representative in everyday use. This duality of transparency and reflectivity is discussed from different points of view by many researchers. Chalmers (Chalmers, 2004) elaborates the coexistence of "seamful" technology and seamless interaction tracing back to philosophical hermeneutics (e.g. Heidegger, 1927) and semiotics. Bolter and Gromala (Bolter \& Gromala, 2004) point to the duality of transparency and reflectivity from an aesthetic point of view and Bødker points out the importance of re-appearing interfaces for experience and reflexivity (Bødker, 2006). In conclusion, in a physical world constantly interweaved with virtual reality and filled with digitally enriched objects, it remains unclear how everyday objects instantiate an interface which is not even needed in everyday interaction.

\section{Bridging the Gap}

Ishii and Ullmer present in (Ishii \& Ullmer, 1997) a number of projects that implement tangible interfaces to some extent. From their analysis they hint on metaphors apt for digital representation display. From their research they found metaphors especially fitting to bridge the real and the virtual world and to integrate seamlessly into real space. Optical metaphors in general have been found to do so quite nicely.

One of these metaphors can be found in the metaDesk project (Ishii \& Ullmer, 1997). MetaDesk combines large scale maps on a desk with movable computer displays. These displays function as magic active lenses and show three dimensional views of the position on hand. The see-through metaphor as magical lens has been presented by Bier et al. as a concept (Bier et al., 1993; Stone et al., 1994) and is used in metaDesk in combination with real environments.

Another option of using a visual metaphor is the idea of digital shadows (Ishii \& Ullmer, 1997). Here real objects cast virtual shadows showing their digital information using real world constraints. They are fitting their display nicely into the real world by mimicking real object properties.

Of course these shadows can either be projected onto the surface or shown virtually by a magical lens. Either way, the objects need additional hardware to implement this functionality to convey their digital information. 


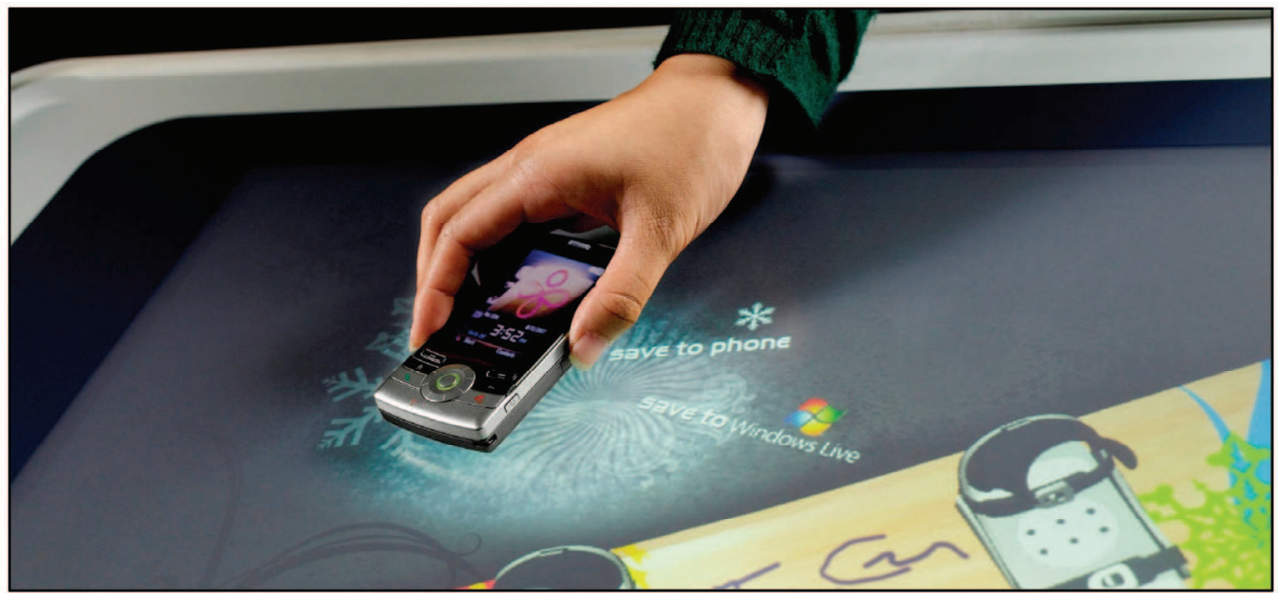

Figure 4. Digital light metaphor on a Microsoft Surface. (Courtesy of Microsoft Corporation)

A closely related imaging solution is the digital light metaphor. Instead of casting shadows, real objects emit virtual light in this case. This metaphor is implemented in the new Microsoft Surface project for example (see Fig. 4). Here objects can be put on a table whose surface is a large display. This way, real objects can be annotated with digital information quite easily (Microsoft Surface, 2008). The digital representation and operations can be shown in an orb surrounding the object, combining the digital light metaphor with Fitzmaurice's idea of a graspable interface in the ActiveDesk project (Fitzmaurice et al., 1995).

The projects briefly presented so far have all one thing in common: they need proper preparation of the environment in order to facilitate interfaces for real objects. All projects need intelligent rooms or need to be at least permanently installed. Nevertheless, even the early projects such as metaDesk demonstrate the benefit of mobile devices: The mobility and the position and configuration in real-space turn even the early devices into useful tools.

The enhancement of mixed reality rooms with mobile devices as described above is the first step towards a seamless integration of real world objects with smart devices like Personal Digital Assistants or Smart Phones. However, a real seamless and integration demands the ubiquity of the virtual information and its display wherever the need and wherever the location. A further development towards this view of ubiquity is presented by Butz and Krüger (Butz \& Krüger, 2006). They present a concept of intelligent rooms which are interconnected with each other. They thereby extend the space digital objects work in and provide the basis to investigate interacting with digitally enhanced objects across the borders of single rooms. For visualisation of digital information and invocation of digital functions they make use of the peephole metaphor (Yee, 2003). The peephole metaphor is similar to the toolglass or magic lens metaphor by Bier et al. (Bier et al., 1993) as mentioned above. Both provide additional information relative to a certain real or virtual position. But where the magic lens metaphor displays more or special information to an object at the coordinates, a peephole display returns only the contents of the virtual layer at that point. This is not necessarily linked to the real world and the objects in it. But with the integration in mixed reality rooms and the connection with objects they become magic lenses or tool glasses. 


\subsection{Small Devices}

With the rise of small devices such as Personal Digital Assistants (PDA) and Smart Phones we nowadays have the possibility of bringing computing power everywhere. The devices are conveniently small and portable. However, these two factors introduce new problems for interaction and interface design. The displays are limited in size due to the dimensions of the device; they have lower resolution and often fewer colours. The aspect ratios differ a lot and there is a great diversity in hardware setup considering onboard memory, computing power, graphical capabilities and energy supply. The interaction possibilities range from touchpads to small keyspads. Constant development reduces these problems but is has to be stated that some of the limitations cannot be eliminated as Chittaro points out (Chittaro, 2006):

The permanent use everywhere and every time introduces the problem of different and even changing surroundings. The size of a PDA or smart phone always causes small displays and interaction with a small device demands for different approaches apt for small devices and usage in motion.

All these points need investigation and demand for new approaches. Pascoe et al. describe the drawbacks of using mobile devices in the field (Pascoe et al., 2000). They especially focus on the environment and environment interaction. The context of use limits the interface in many ways. The difference in lighting is clearly a factor for mobile interfaces and their use of colour and contrast. Even more important is the simple act of moving introduces problems in device handling and especially reduces the mental capacities free for interaction as other tasks interfere.

\subsection{Peephole Displays}

The peephole metaphor (Yee, 2003) is a solution especially designed for small devices reducing the drawback of the small display. It combines nicely the interaction possibilities of a small device with the idea of expanding the display. Instead of the actual display and its limited size, it brings together movement as input with clipping, resulting in a much larger virtual screen.

This concept can be seen as an extension of Fitzmaurice idea of an extensional workspace using spatially aware palmtop computers (Fitzmaurice, 1993). An example for this paradigm is the active map application. Here moving a small device to a certain position in front of a wall map results in the display of additional information for this location. The static 2D map is enhanced with up to date dynamic information. Beside the very intuitive example Fitzmaurice presents other scenarios for interactive libraries offices and living rooms. The data presented ranges from completely virtual information like calendar data and stock market prices to virtual 3D views of certain locations.

The concept of peephole displays is an extension to Fitzmaurice' work as it combines the large virtual display with interaction on the displayed data. Yee uses today's input techniques like pen interaction and hand writing recognition for data manipulation. Interaction here is not only used to move the virtual layer, bringing up intended information, but also to manipulate this information in place Fig. 5 shows a peephole display being used in a calendar application.

Clearly, the peephole metaphor is a step towards ubiquitous computing as it opens windows to the virtual world. Notably, the introduction of the interaction concept makes known interfaces and application available on the move, making the limitation of small 
screen disappear. Unlike Fitzmaurice's principle this extension allows for porting desktop application onto palmtops. The integration into the environment is no integral part of this metaphor. In fact, it leaves this option untouched and open.

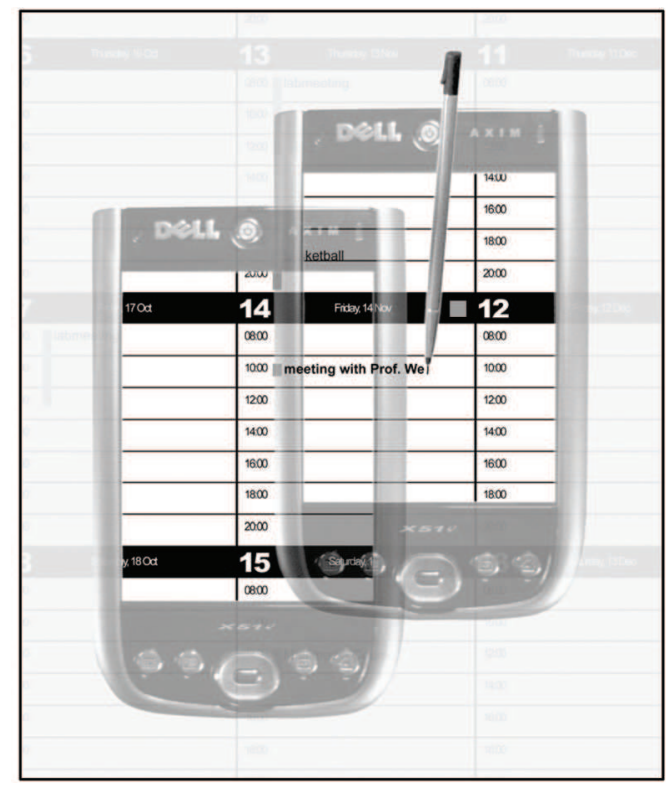

Figure 5. Writing on a Peephole Display. Moving the device allows for viewing different parts of the virtual document while simultaneous editing is possible. (Yee, 2003)

The usage of the peephole metaphor is restricted to bringing virtual content into the real world. But it can also be used the other way around. A nice example for bringing the mobility and spatial awareness of a device to the virtual world is presented by Hachet et al. (Hachet et al., 2005). They use a mobile device capable of displaying 3D graphic to interact with the objects in the virtual world. The mobile device in this case acts as a window in the virtual world. The movements of special objects in the real world and the movements of the small device itself affect the configuration of the virtual world.

\subsection{Mobile Augmented Reality}

Augmented Reality solutions are getting more and more common (Schmalstieg et al., 2002; Looser et al., 2004) and some even use mobile devices (Butz \& Krüger, 2006) but today's mobile devices have the computational power to generate and render 3D scenes in real-time themselves. The devices are capable of virtual reality rendering enabling rich virtual worlds and new interaction techniques induced by the mobile devices (Hachet et al., 2005; Hwang et al., 2006; Çapın et al., 2006).

Bringing virtual reality techniques together with real world images and videos make way for the superimposition of digital information into real world views, following closely the Magic Lense paradigm in the domain of 3D imaging (Bier et al., 1993; Viega et al., 1996).

First concepts for virtual windows range back to Gaver et al. (Gaver et al., 1993) who describe a system which turns a monitor into a virtual window bringing together real-world 
interaction with camera display. Clearly this project is not yet an Augmented Reality system as it does not use superimposition but it already describes and masters the problem of bringing together real world perspective view and a virtual model.

Henrysson et al. show an example for a classical AR application ported to a mobile device, making use of the interaction possibilities offered by a smart phone (Henrysson et al., 2005). The phone equipped with a camera is enabled to track markers, thus being able to track the position relative to the enhanced room. According to that, virtual objects can be placed in the natural environment. The difference to classical AR applications lies in the limited interaction possibilities of the small device on which special attention is posed on here. Though the obvious drawback of the limited keyboard the mobile device provides a six degree of freedom (6 DOF) mouse.

Its mobility can be used for augmented world interaction similar to the peephole example presented above. Nevertheless, this solution focuses on interaction with virtual world objects. The superimposition is not dependant on the special location. The marker system set up is only needed to enable tracking in 6 DOF interactions.

The full capabilities of mobile device application in augmented reality are shown by Wagner et al. in the invisible train system (Wagner et al., 2005). Here a virtual toy train can be steered by interaction with a small device.

In contrast to the just described system by Henrysson, the invisible train system makes massive use of real world interaction. The virtual train runs on real wooden railroad tracks generating an immersive environment with nicely fitting metaphors. The user takes the role of a signalman keeping the train on the right track. There are real crossings for which the junctions have to be operated. This can be done on the device using pen interaction (see Fig. 6).

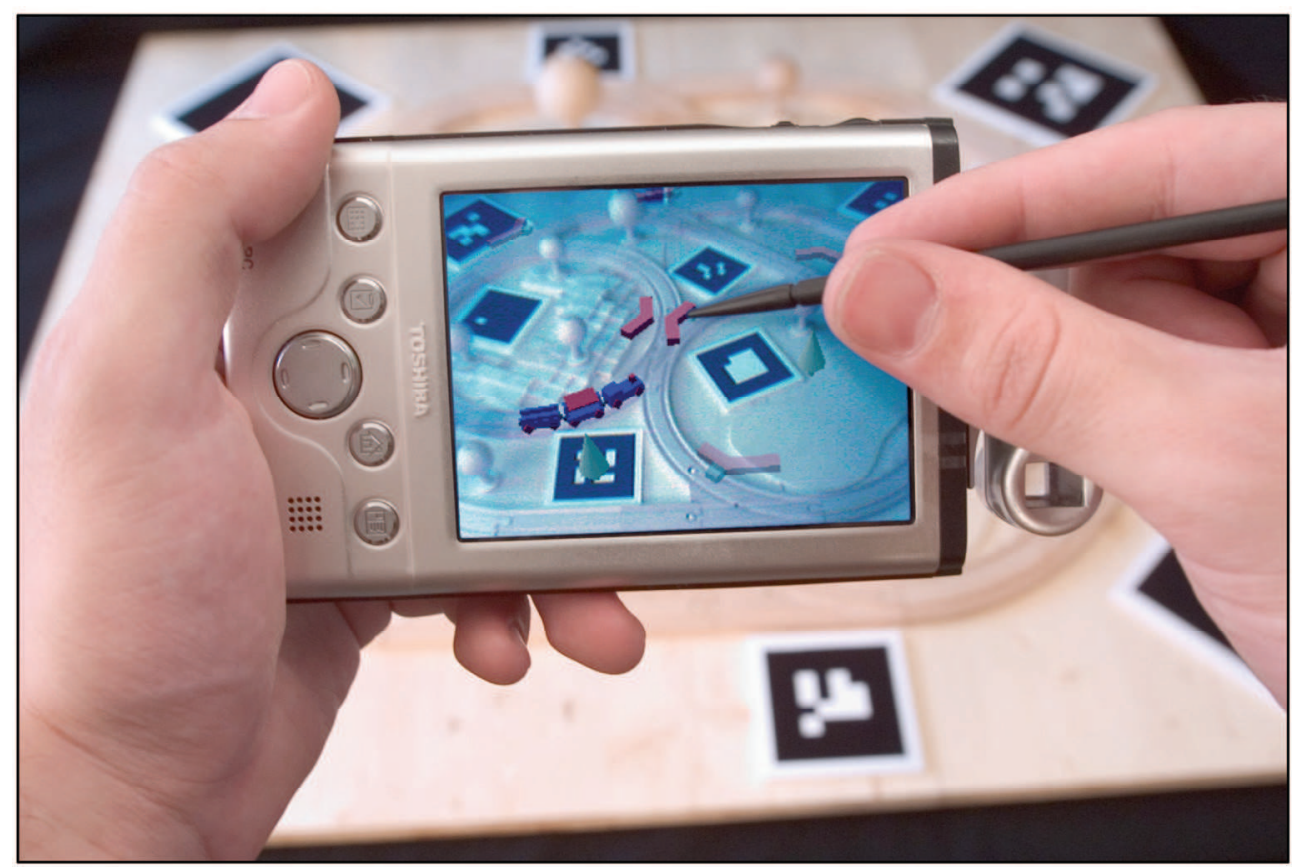

Figure 6. The Invisible Train application. (Courtesy of Vienna University of Technology) 
The invisible train application can even be played as a game with up to four players. All of them have constant and simultaneous access to all invisible train elements. They all can set junctions and prevent trains from crashing; they all get the same view of the current situation only differing in perspective depending on their viewpoint.

The interesting point here is not the fact that this application is multi user capable, but the degree of immersion being achieved. The virtual objects and interfaces integrate smoothly into a real environment. They react as if they were real, imitating their real prototypes, providing a suitable interface metaphor and implementing their functionalities.

Together with the heavy use of real objects as reference points not only with markers for tracking but especially with the wooden rails to get across the mental model, this application allows for a very high degree of immersion. The seamless integration of virtual objects into a real environment allows for true augmented reality and follows the vision of a physical world interwoven with virtual reality.

A drawback of most of the existing augmented reality applications is their dependency on an environment especially prepared for tracking purposes. As a result most of the environments are plastered with tags, patterns easily recognized by the tracking hardware. Thus, furthermost careful preparation of the spot is needed and often calibrations have to be conducted, a problem that has to be solved for ubiquitous computing to become reality.

\subsection{Context Aware Mobile Computing}

The increasing density of sensory equipment present in our surrounding together with the increasing sensory repository of today's mobile devices make way for context adaptable systems. The strong linkage between context and ubiquitous computing, its important role for seamless device integration and proactive system behaviour is recognized and researched by a whole research community. Especially the notion and comprehension of context and its diversity is subject of research.

Abstractly, context can be defined as the attributions of an entity depending on its surrounding, where an entity can be a device or a human being and the surrounding a situation or environment. Here, different kinds of surrounding can be determined:

At first and most notable, the real surrounding can be understood as context. This physical context can for example be a location of a real entity, its orientation but also environmental attributes like brightness, lighting or temperature.

Second, the social context or the situation a user is in at a certain location can be taken into account. Interaction with people in general belongs to this section. For instance, cultural constraints have to be met, certain behaviour may be inappropriate in a certain social situation or it may just be right under those circumstances only.

Third, the condition the user is in can be taken in account. His emotional state may be interesting for certain applications, notifications or distractions should be kept to a minimum, according to the user's state (Pascoe et al., 1999; Want et al., 1999; Pascoe et al. 2000; Schmidt, 2002; Messeter et al. 2004; Ho \& Intille, 2005).

With mobile devices, another most notable point is added to this diversion. As Messeter et al. point out, mobile devices enables the user to detach from his context as they allow for applications to become mobile and reachable whenever and wherever desired (Messeter et al. 2004). The user therefore takes a virtual context with him, carried by the smart device rather than interacting with the context at hand. 


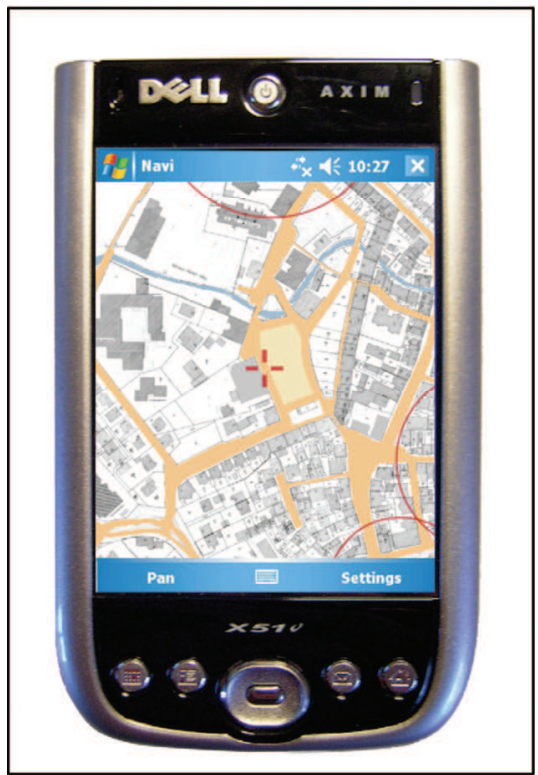

Figure 7. A context aware application using Halo circles to show off screen locations (Mahler et al. 2007)

Clearly, context awareness as well as mobility allow for new adaptive systems. Depending on the application a special notion of context is used and implemented. Yet, new possibilities pose new challenges for device interaction and interfaces. Context can not only be used for the application itself but also to enable new ways of interaction or, depending on the application, use additional sensory information for data visualization.

Ho and Intille for instance present a way of how to reduce the perceived interruption burden in mobile device usage. They analyse the user's condition and the degree of his activity and concentration. By that they can shift distractive messages to times when the user shifts tasks in order to reduce the degree of distraction (Ho \& Intille, 2005). The notion of user attention and its importance for the interface is found to be a very important and valuable resource in mobile computing by other researchers as well (see Pascoe et al., 2000). However, for ubiquitous computing to seamlessly integrate into the real world it is crucial to seamlessly recognize context and to integrate existing sensory information (Pascoe et al., 1999).

An example for seamless integration of context in a mobile application, especially its visualization, and its reduction of the user's burden is shown by Mahler et al. (Mahler et al. 2007). For a pedestrian navigation system different visualization techniques were analysed and evaluated with special regard to the cognitive load. The application makes use of physical context, especially location and orientation. According to the current attribution a map sector is shown (see Fig. 7). This introduces the problem that some points of interest (POIs) for the task at hands are located outside the part of the map currently shown. By only adapting the user interface in using a special visualization method, it could be shown that the user's burden is reduced significantly. The visualization in use, the Halo circle metaphor by Baudisch and Rosenholtz proposes to draw circles around off screen POIs. The on screen 
circle segments then allow the user to easily estimate the location of each off screen POI (Baudisch \& Rosenholtz, 2003).

This example shows the possibilities made available by context usage. Additionally, the important role of a suitable interface for mobile device interaction is illustrated. The integration of context for interface control and its combination with apt visualization techniques leads to new and improved interfaces as shown above. These steps together with the integration and location of context information are necessary to make the vision of ubiquitous computing and its benefits come true.

\subsection{Mobile Devices and Tangible Interfaces}

From our point of view the seamless integration of the ideas described above is the goal. Intelligent environments offer opportunities, we are only at the very beginning to understand or being able to implement. Nevertheless, the sensory equipment needed along with the computational power, cannot be implemented and reach everywhere. There will still be places that cannot provide the needed equipment for full mixed reality and complete transparency. A possible solution to this is to take the computing power with us to these spaces. Of course there are some drawbacks in this case as we can only use what we bring with us and we do not intend to install huge environments. We rather think that the key lies in the seamless integration of mobile devices in the vision of intelligent environments, ubiquitous computing and tangible interfaces. This does not seem to be too farfetched as we can observe a rapid increase in both the computing power and the sensory capabilities of mobile devices.
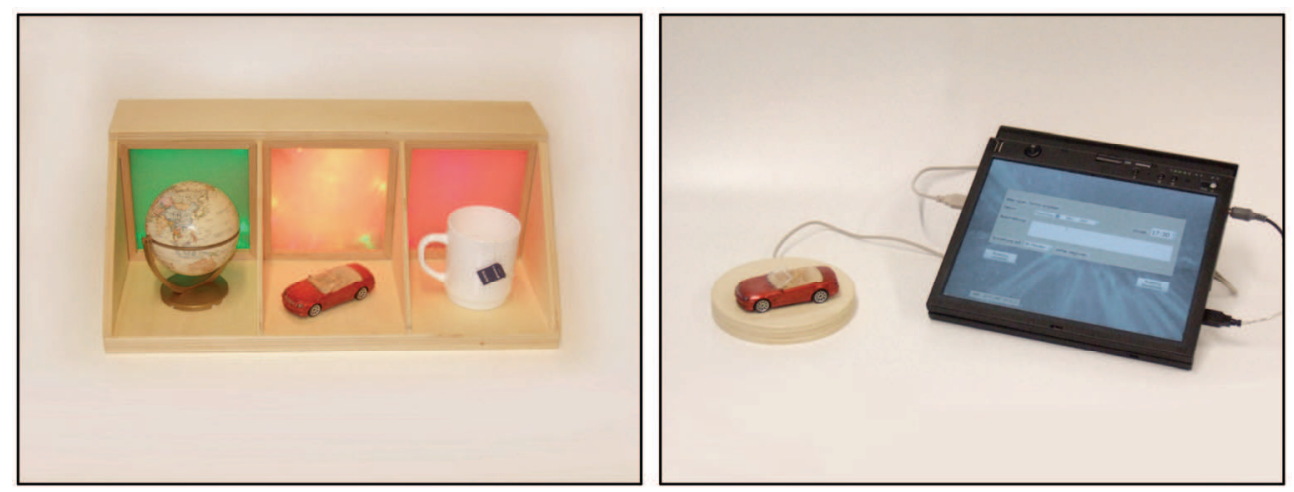

Figure 8. The two components of the Tangible Reminder: On the left, the ambient display subsystem with tangible personal objects in different states of urgency coded by colour. On the right the original input solution consisting of a tablet $\mathrm{PC}$ with touch screen and the coding plate

Furthermore we do not think that the goal of these new paradigms should be to replace existing solutions but rather to integrate them into the existing environment to enrich our world and carefully replace where better solutions are provided. Mobile devices have the potential to pave an evolutionary road towards truly pervasive ubiquitous computing. Bødker formulates similar goals for what she calls third wave challenges (Bødker, 2006). In our institute we are working on different projects tackling the field of ubiquitous computing. The example we want to present here focuses especially on the convergence of tangible interaction and ambient displays. 
We have included a brief overview of the Tangible Reminder in the following, for further reading a detailed description can be found in (Hermann et al., 2007). The goal of the Tangible Reminder was to create an easy to use and comprehensible physical installation to deal with appointments and deadlines. The first version of this system consists of two parts, an ambient display subsystem which is capable of holding tangible objects and showing the states of their digital representative and an input subsystem to connect and change digital information associated with an object (see Fig. 8).

The display part integrates in everyday life smoothly as it makes use of ambient technology to deliver the status of an object at a glance and stays in the background otherwise. To convey the urgency state of an appointment the Tangible Reminder maps the urgency level onto three colours following cultural constraints. The colours used are green for far away deadlines, yellow for approaching ones and red for urgent deadlines. Additionally the light starts flashing when an appointment is due. This way the display is no more ambient but pressing and draws the user's attention when needed.

The Tangible Reminder's display subsystem has a tangible interface and is operated by actions with graspable objects. The objects used can be chosen freely. As stated earlier this supports the strong mental linkage between an object and its digital representation.

To associate an appointment with an object the input subsystem is used. By placing the object in question on the programming plate an interaction mask appears on the tablet PC. Here the properties of an appointment can be defined or changed. The input subsystem can also be used as a viewer to display associations between task and objects.

Clearly, the use of the Tangible Reminder detaches appointments from the computer, a way of keeping track of deadlines today. It gives the deadline a physical representation and allows for appointment management. It provides a solution that works through interaction of personal objects with an ambient display system. The Tangible Reminder stays in the background providing information at a glance and additionally comes forward and warns of due deadlines when necessary.

Although the Tangible Reminder is already a convenient system for appointment management it falls short when it comes to appointment linkage. The use of a tablet PC with handwriting as input method is a step into the right direction, but it clearly is still a rather computerized solution. Still a computer interface has to be used for the coupling of appointment and object.

This is true for simple appointments. But we have already taken steps to push the computer further to the background. By distinguishing three different kinds of appointments we can get rid of the regular programming for every appointment. The usual appointment has one deadline, which can be specified by an absolute date. In contrast to that relative deadlines allow for simple programming by action. The simple act of putting an object linked to a relative deadline programs the Tangible Reminder, it is programmed by implied action. A nice example that conveys this idea is the tea cup - the Tangible Reminder can help to prevent that the tea is brewed too long. Simply by putting the cup into the Reminder the relative deadline gets programmed and thus the system will remind us in say three minutes. Similar to the relative deadline and an extension to it is the multiple deadline approach. Here a multitude of appointments can be bound to one object. These objects can remind us on different deadlines with just one object. This is very neat if we think of a medication box. Put into a Reminder tray the box itself will remind us on the times to take medicine. 
These examples clearly show the urge to get rid of the computer. However, the problem of how these objects get linked in the first place remains unclear. Furthermore the objects lack an interface for reflection purpose.

To tackle this circumstance we turned our attention to the intertwining of ubiquitous computing and mobile devices, Personal Digital Assistants (PDA) in this case. A PDA capable of recognizing a personal digitally enhanced object can fill in for the input subsystem used in the first version of the Tangible Reminder. Clearly, this is not a seamless way of enhancing the physical environment. It rather follows the idea of bringing together new ways of interaction with known and approved technology. For implementation purpose we decided to follow the digital lens metaphor. The PDA thus embodies a window to the digital world (Bier et al., 1994; Viega et al., 1996; Looser et al., 2004), representing all information associated with the close by physical object. It therefore embodies an extension of an existing real object into the digital realm.

The use of the PDA as mobile interface acts as a tool glass offering virtual information for the close by real object. It presents its linked virtual information and allows for editing. We chose this approach to be independent of a special room and extensive preparation. Instead we focus on the seamless integration of the virtual tool glass and rather accept minor inaccuracies in rendering compared to a fully equipped mobile AR system. Even the use of conventional mobile interfaces is an option in this application as it is completely consistent with the magic lens (Bier et al., 1993) or the peephole metaphor (Yee, 2003). Clearly this approach needs further investigation, nevertheless it is a promising approach to combine tangible interfaces and ubiquitous computing, lending real objects a mobile interface.

\section{Conclusion}

In a world of constant intertwining of virtuality and reality a consistent way of discovering links between the real and the virtual world is needed. Clearly, the interaction with real world objects offers new possibilities for interfaces to reduce task complexity and to embed virtual tasks into the real world. However, this leads to problems in device use. Readymades in our everyday environment already have a function, expressed in its physical form. To link such objects with additional virtual options leads to the question of how such a linkage can be made comprehensible.

The construction of reactive environments and intelligent rooms with huge amounts of sensing equipment is a well witnessed direct result. And within these interface metaphors are developed, that allow for the seamless integration of real and virtual objects. Where these intelligent environments come close to Weisers' vision of transparency, they fall short in behave of ubiquity. In this situation mobile devices can fill in. While our environment is not fully equipped with sensors, mobile devices can extend local installations by taking the computational power and the sensory equipment with the user. Acting as magic lenses, they can provide everyday objects with the interfaces needed for device usage. They can display the functions an object provides; they can help in setting up linkages and even help with reconfiguration.

At the same time, the mobile devices, acting as virtual tool glasses, can provide an interface only when needed, reflecting the dynamic role an object can play depending on the context the object is used in. Thus, the mobile device, giving real word objects an interface, can be used as tool to scale virtuality to the extend needed. 
From our point of view the great challenge ahead is the seamless integration of the many different promising ideas described above. Living in intelligent environments, interacting in natural ways is the great goal. Nevertheless, these solutions require a considerable amount of ubiquitous and omnipresent hardware, sensors, actuators and computing power. Even if we manage to accomplish this tremendous effort for our living environments or work spaces, there will be still spaces we cannot equip with the required systems. That is where mobile devices can fill in.

\section{References}

Azuma, R. (1997). A Survey of Augmented Reality. Presence: Teleoperators and Virtual Environments, Vol. 6, No. 4, (August 1997), pp. 355-385, 10547460.

Baudisch, P. \& Rosenholtz, R. (2003). Halo: a technique for visualizing off-screen objects. Proceedings of the SIGCHI Conference on Human Factors in Computing Systems, pp. 481488, 1581136307, Ft. Lauderdale, April 2003, ACM, New York.

Beigl, M., Gellersen, H. \& Schmidt, A. (2001). Mediacups: experience with design and use of computer-augmented everyday artefacts. Computer Networks: The International Journal of Computer and Telecommunications Networking, Vol. 35, No. 4, March 2001, pp. 401-409, 13891286.

Bier, E., Stone, M., Pier, K., Buxton, W. \& DeRose, T. (1993). Toolglass and magic lenses: the see-through interface, Proceedings of the 20th Annual Conference on Computer Graphics and interactive Techniques SIGGRAPH '93, 0897916018, pp. 73-80, ACM, New York.

Bier, E., Stone, M., Fishkin, Buxton, W. \& Baudel, T. (1994). A taxonomy of see-through tools. Proceedings of the SIGCHI Conference on Human Factors in Computing Systems: Celebrating interdependence, pp. 358-364, 0897916506, Boston, April 1994, ACM, New York.

Bødker, S. (2006). When second wave HCI meets third wave challenges. Proceedings of the 4th Nordic Conference on Human-Computer interaction: Changing Roles, pp. 1-8, 1595933255, Oslo, October 2006, ACM Press, New York.

Bolter, J. \& Gromala, D. (2004). Transparency and Reflectivity: Digital Art and the Aesthetics of Interface Design, In: Aesthetic computing, Fishwick, P. (Ed.), pp. 369-382, MIT Press, 0-262-06250-X.

Butz, A. \& Krüger, A. (2006). Applying the Peephole Metaphor in a Mixed-Reality Room. IEEE Computer Graphics and Applications ,Vol. 26, No. 1, January/February 2006, pp. 56-63, 02721716.

Çapın, T., Haro, A., Setlur, V. \& Wilkinson, S. (2006). Camera-Based Virtual Environment Interaction on Mobile Devices, Lecture Notes in Computer Science, Vol. 4263/2006, October 2006, pp. 765-773, Springer, 9783540472421, Berlin.

Chalmers, M. (2004). Coupling and Heterogeneity in Ubiquitous Computing, ACM CHI 2004 Workshop Reflective HCI: Towards a Critical Technical Practice.

Chittaro, L. (2006). Visualizing Information on Mobile Devices, Computer, Vol. 39, No.3, March 2006, pp. 40-45, 00189162.

Cohen, P. (1992). The Role of Natural Language in a Multimodal Interface, Proceedings of the 5th annual ACM symposium on User interface software and technology, pp. 143-149, 0897915496, Monteray, California, November 1992, ACM, New York. 
Fitzmaurice, G. W. (1993). Situated information spaces and spatially aware palmtop computers. Communications of the ACM, Vol. 36, No. 7, July 1993, pp. 39-49, 00010782.

Fitzmaurice, G., Ishii, H. \& Buxton, W. (1995). Bricks: laying the foundations for graspable user interfaces, Proceedings of the SIGCHI Conference on Human Factors in Computing Systems, pp. 442-449, 0201847051, Denver, May 1995, ACM Press/Addison-Wesley Publishing Co., New York.

Gaver, W., Smets, G. \& Overbeeke, K. (1995). A Virtual Window on media space. Proceedings of the SIGCHI Conference on Human Factors in Computing Systems, pp. 257-264, 0201847051, Denver, May 1995, ACM Press/Addison-Wesley Publishing Co., New York.

Hachet, M., Pouderoux, J. \& Guitton, P. (2005). A camera-based interface for interaction with mobile handheld computers. Proceedings of the 2005 Symposium on interactive 3D Graphics and Games, pp. 65-72, 1595930132, Washington, April 2005, ACM, New York.

Hermann, M., Mahler, T., Melo, de G. \& Weber, M. (2007). The tangible reminder. Proceedings of 3rd IET International Conference on Intelligent Environments, pp. 144151, 9780863418532, Ulm, September 2007.

Heidegger, M. (1927). Sein und Zeit, In: Jahrbuch für Phänomenologie und phänomenologische Forschung, Vol. 8, Husserl, E. (Ed.).

Henrysson, A., Ollila, M. \& Billinghurst, M. (2005). Mobile phone based AR scene assembly. Proceedings of the 4th international Conference on Mobile and Ubiquitous Multimedia, pp. 95-102, 0473106582, Christchurch (New Zealand), December 2005, ACM, New York.

Ho, J. \& Intille, S. (2005). Using context-aware computing to reduce the perceived burden of interruptions from mobile devices. Proceedings of the SIGCHI Conference on Human Factors in Computing Systems, pp. 909-918, 1581139985, Portland, April 2005, ACM, New York.

Holmquist, L.; Schmidt, A. \& Ullmer, B. (2004). Tangible Interfaces in Perspective, Personal Ubiquitous Computing, Vol. 8, No. 5, September 2004, pp. 291-293, 16174909.

Hornecker, E. \& Buur, J. (2006). Getting a grip on tangible interaction: a framework on physical space and social interaction, Proceedings of the SIGCHI conference on Human Factors in computing systems, pp. 437-446, 1595933727, Montréal, April 2006, ACM, New York.

Hoven, E. van den \& Eggen, J. (2004). Tangible Computing in Everyday Life: Extending Current Frameworks for Tangible User Interfaces with Personal Objects, Lecture Notes in Computer Science, Vol. 3295/2004, October 2004, pp. 230-242, Springer, 03029743, Berlin.

Hoven, E. van den \& Eggen, J. (2005). Personal souvenirs as Ambient Intelligent objects, Proceedings of the 2005 Joint Conference on Smart Objects and Ambient intelligence: innovative Context-Aware Services: Usages and Technologies, pp. 123-128, 1595933042, Grenoble, October 2005. ACM Press, New York.

Hwang, J., Jung, J. \& Kim, G. (2006). Hand-held virtual reality: a feasibility study. Proceedings of the ACM Symposium on Virtual Reality Software and Technology, pp. 356363, 1595933212, Limassol (Cyprus), November 2006, ACM, New York. 
Ishii, H. \& Ullmer, B. (1997). Tangible Bits: Towards Seamless Interfaces Between People Bits and Atoms, Proceedings of the SIGCHI conference on Human factors in computing systems, pp. 234-241, 0897918029, Atlanta, March 1997, ACM, New York.

Looser, J., Billinghurst, M. \& Cockburn, A. (2004). Through the looking glass: the use of lenses as an interface tool for Augmented Reality interfaces. Proceedings of the 2nd international Conference on Computer Graphics and interactive Techniques in Australasia and South East Asia, pp. 204-211, 1581138830, Singapore, June 2004, ACM, New York.

Mahler, T., Reuff, M. \& Weber, M. (2007). Pedestrian Navigation System Implications on Visualization, Lecture Notes in Computer Science, Vol. 4555/2007, August 2007, pp. 470-478, Springer, 9783540732808, Berlin.

Messeter, J., Brandt, E., Halse, J. \& Johansson, M. (2004). Contextualizing mobile IT. Proceedings of the 5th Conference on Designing interactive Systems: Processes, Practices, Methods, and Techniques, pp. 27-36, 1581137877, Cambridge, August 2004, ACM, New York.

Microsoft Surface. http://www.microsoft.com/surface/, visited July 19th, 2008.

Milgram, P. \& Kishino, F. (1994). A Taxonomy of Mixed Reality Visual Displays, IEICE Transactions on Information Systems, Vol. E77-D, No. 12, December 1994, pp. 13211329.

Norman, D. (1988). The Psychology of Everyday Things, Basic Books, 0465067093, New York.

Norman, D. (1998). The Invisible Computer: Why Good Products Can Fail, the Personal Computer Is So Complex, and Information Appliances Are the Solution, The MIT Press, 0262640414, Cambridge.

Pascoe, J., Ryan, N. \& Morse, D. (1999). Issues in Developing Context-Aware Computing. Proceedings of the 1st international Symposium on Handheld and Ubiquitous Computing, pp. 208-221, Karlsruhe, September 1999, Springer-Verlag, London.

Pascoe, J., Ryan, N. \& Morse, D. (2000). Using while moving: HCI issues in fieldwork environments. ACM Transactions on Computer-Human Interaction, Vol. 7, No. 3, September 2000, pp. 417-437, 10730516.

Rath, M. \& Rocchesso, D. (2005). Continuous Sonic Feedback from a Rolling Ball, IEEE MultiMedia, Vol. 12, No. 2, April 2005, pp. 60-69, 1070986X.

Schmalstieg, D., Fuhrmann, A., Hesina, G., Szalavári, Z., Encarnaçäo, L. M., Gervautz, M. \& Purgathofer, W. (2002). The studierstube augmented reality project. Presence: Teleoperators and Virtual Environments, Vol. 11, No. 1, February 2002, pp. 33-54 10547460.

Schmidt, A. (2002). Ubiquitous Computing - Computing in Context, Ph.D. Thesis, November 2002, Lancaster University.

Shimoga, K. (1992). A Survey of Perceptual Feedback Issues in Dexterous Telemanipulation: Part I-Finger Force Feedback, Proceedings of VRAIS 93, IEEE Press, Piscataway, N.J., 1993, pp. 263-270.

Shimoga, K. (1992). A Survey of Perceptual Feedback Issues in Dexterous Telemanipulation: Part II-Finger Touch Feedback, Proceedings of VRAIS 93, IEEE Press, Piscataway, N.J., 1993, pp. 271-279.

Stone, M., Fishkin, K. \& Bier, E. (1994). The movable filter as a user interface tool. Proceedings of the SIGCHI Conference on Human Factors in Computing Systems: Celebrating interdependence, pp. 306-312, 0897916506, Boston, April 1994, ACM, New York. 
Ullmer, B. \& Ishii, H. (2000). Emerging Frameworks for Tangible User Interfaces, IBM Systems Journal, Vol. 39, No. 3-4, 2000, pp. 915-931.

Ullmer, B. \& Ishii, H. (2001). Emerging Frameworks for Tangible User Interfaces, In: HumanComputer Interaction in the New Millenium, Carroll, J. (Ed.), pp. 579-601, AddisonWesley, 0201704471.

Viega, J., Conway, M., Williams, G. \& Pausch, R. (1996). 3D magic lenses. Proceedings of the 9th Annual ACM Symposium on User interface Software and Technology, pp. 51-58, 0897917987, Seattle, November 1996, ACM, New York.

Wagner, D., Pintaric, T. \& Schmalstieg, D. (2004). The invisible train: a collaborative handheld augmented reality demonstrator. In ACM SIGGRAPH 2004 Emerging Technologies, Elliott-Famularo, H. (Ed.), p. 6, ACM, 1595938962, New York.

Wagner, D., Pintaric, T., Ledermann, F. \& Schmalstieg, D. (2005). Towards Massively Multiuser Augmented Reality on Handheld Devices, Lecture Notes in Computer Science, Vol. 3468/2005, May 2005, pp. 208-219, Springer, 03029743, Berlin.

Want, R., Fishkin, K., Gujar, A. \& Harrison, B. (1999). Bridging physical and virtual worlds with electronic tags. Proceedings of the SIGCHI Conference on Human Factors in Computing Systems: the CHI Is the Limit, pp. 370-377, 0201485591, Pittsburgh, May 1999, ACM, New York.

Weber, M. \& Hermann, M. (2008). Advanced Hands and Eyes Interaction, In: Handbook of Research on Ubiquitous Computing Technology for Real Time Enterprises, Mühlhäuser, M. \& Gurevych, I. (Eds.), pp. 445-469, Information Science Reference, 9781599048321, Hershey.

Weiser, M. (1991). The Computer for the 21 ${ }^{\text {st }}$ century, Scientific American, Vol. 265, No. 3, September 1991, pp. 94-105.

Yee, K. (2003). Peephole displays: pen interaction on spatially aware handheld computers. Proceedings of the SIGCHI Conference on Human Factors in Computing Systems, pp. 1-8, 1581136307, Ft. Lauderdale, April 2003. ACM, New York. 


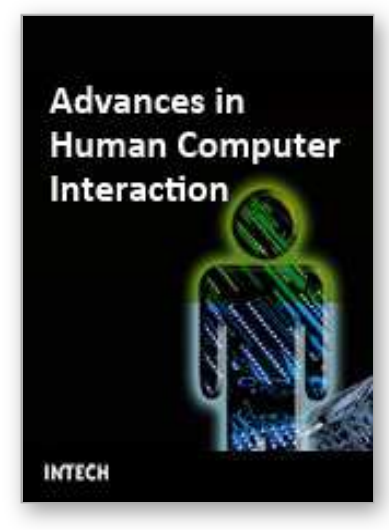

\section{Advances in Human Computer Interaction \\ Edited by Shane Pinder}

ISBN 978-953-7619-15-2

Hard cover, 600 pages

Publisher InTech

Published online 01, October, 2008

Published in print edition October, 2008

In these 34 chapters, we survey the broad disciplines that loosely inhabit the study and practice of humancomputer interaction. Our authors are passionate advocates of innovative applications, novel approaches, and modern advances in this exciting and developing field. It is our wish that the reader consider not only what our authors have written and the experimentation they have described, but also the examples they have set.

\section{How to reference}

In order to correctly reference this scholarly work, feel free to copy and paste the following:

Thorsten Mahler and Michael Weber (2008). Mobile Device Interaction in Ubiquitous Computing, Advances in Human Computer Interaction, Shane Pinder (Ed.), ISBN: 978-953-7619-15-2, InTech, Available from: http://www.intechopen.com/books/advances_in_human_computer_interaction/mobile_device_interaction_in_u biquitous_computing

\section{INTECH}

open science | open minds

\author{
InTech Europe \\ University Campus STeP Ri \\ Slavka Krautzeka 83/A \\ 51000 Rijeka, Croatia \\ Phone: +385 (51) 770447 \\ Fax: +385 (51) 686166 \\ www.intechopen.com
}

\author{
InTech China \\ Unit 405, Office Block, Hotel Equatorial Shanghai \\ No.65, Yan An Road (West), Shanghai, 200040, China \\ 中国上海市延安西路65号上海国际贵都大饭店办公楼 405 单元 \\ Phone: +86-21-62489820 \\ Fax: $+86-21-62489821$
}


(C) 2008 The Author(s). Licensee IntechOpen. This chapter is distributed under the terms of the Creative Commons Attribution-NonCommercialShareAlike-3.0 License, which permits use, distribution and reproduction for non-commercial purposes, provided the original is properly cited and derivative works building on this content are distributed under the same license. 